\title{
Phase II study of Ifosfamide+Doxorubicin in patients with advanced synovial sarcomas (E1793): a trial of the Eastern Cooperative Oncology Group
}

\author{
JOHN H. EDMONSON ${ }^{1}$, LOUISE M. RYAN ${ }^{2}$, CARLA I. FALKSON ${ }^{3}$, \\ DAVID G. HICKS ${ }^{4} \&$ RONALD H. BLUM ${ }^{5}$ \\ ${ }^{1}$ Mayo Clinic, Rochester, $M N ;{ }^{2}$ Dana Farber Cancer Institute, Boston, $M A ;{ }^{3}$ University of Alabama, Birmingham, AL; \\ ${ }^{4}$ ViaHealth Rochester General Hospital, Rochester, NY, ${ }^{5}$ Beth Israel Medical Center, New York, NY, USA
}

\begin{abstract}
Purpose Because we had observed in the synovial sarcoma subgroup of a broad phase III advanced soft tissue sarcoma study a significantly greater objective regression rate from ifosfamide+doxorubicin (88\%) than from doxorubicin alone $(20 \%)$ $(P=0.02)$, the Eastern Cooperative Oncology Group (ECOG) decided to further assess this two drug combination in a subsequent Phase II study.

Patients Between 1994 and 1999, twelve adult patients with advanced synovial sarcomas were enrolled to receive, as their initial chemotherapy, ifosfamide $7.5 \mathrm{gm} / \mathrm{m}^{2}$ plus doxorubicin $60 \mathrm{mg} / \mathrm{m}^{2}$, given intravenously over two consecutive days every 3 weeks.

Methods Each day for 2 days doxorubicin $30 \mathrm{mg} / \mathrm{m}^{2}$ was infused over $5 \mathrm{~min}$ through a running i.v., followed by ifosfamide $3750 \mathrm{mg} / \mathrm{m}^{2}$ over $4 \mathrm{~h}$. Continuous i.v. fluid was infused at $300 \mathrm{~mL} / \mathrm{h}$ for $3 \mathrm{~h}$ on day 1 , before chemotherapy was begun; then the infusion was continued at $100 \mathrm{~mL} / \mathrm{h}$ for a total of 3 days. Mesna $750 \mathrm{mg} / \mathrm{m}^{2}$ was given $15 \mathrm{~min}$ before ifosfamide and at 4 and $8 \mathrm{~h}$ after ifosfamide on days 1 and 2 of each treatment cycle. Filgrastim (G-CSF) $5 \mu \mathrm{g} / \mathrm{kg}$ was given subcutaneously each day for 14 days beginning on day 3 of each treatment cycle to limit the severity of neutropenia.

Results Five of our 12 patients (42\%) experienced partial regression of their advanced synovial sarcomas; however, this first stage result was borderline for proceeding to the second planned stage of accrual and our case accrual was quite poor. Thus, the study was closed after stage one accrual. Our patients received a median of four cycles of chemotherapy (range: 1 to 6). All patients experienced at least grade 3 neutropenia (grade 4 in nine of them), and one patient died of treatment-related sepsis following the initial cycle of chemotherapy. Median survival was 11 months.
\end{abstract}

Key Words: Author please provide keywords ???

\section{Introduction}

Among the soft tissue sarcomas synovial sarcoma is reported to be one of the more responsive to systemic chemotherapy. ${ }^{1,2}$ Analysis of the small synovial sarcoma subgroup within a phase III study by ECOG appeared to support this thesis for only the combination of ifosfamide and doxorubicin, as compared with doxorubicin alone. ${ }^{3}$ In that exploratory subgroup analysis the two-drug regimen with an objective regression rate of $88 \%$ appeared significantly better $(P=0.02)$ than doxorubicin alone $(20 \%)$. We suspected that this result might be youth related. Our present phase II study was designed to better assess that remarkably high tumor regression rate in advanced synovial sarcoma patients receiving ifosfamide plus doxorubicin.

\section{Patients}

Patients at least 15 years old with histologically confirmed synovial sarcoma were enrolled if they had residual, recurrent or metastatic disease measurable by physical examination, X-rays, CT scanning or MRI. All patients had ECOG performance status ratings of 0,1 , or 2 . Satisfactory bone marrow function, renal function, and hepatic function were recognized, respectively by baseline leukocyte counts of $\geq 4000 / \mu \mathrm{L}$, platelet counts of $\geq 125000 / \mu \mathrm{L}$, and hematocrit of $\geq 28 \%$; serum creatinine $\leq 1.5 \mathrm{mg} / \mathrm{dL}$; and serum bilirubin of $\leq 2 \mathrm{mg} / \mathrm{dL}$. The patients were free of significant infection or other serious illness that might be aggravated by this chemotherapy. None of the patients had previously received cancer chemotherapy, and no previously irradiated lesion 
was considered measurable unless it had grown at least $25 \%$ since radiotherapy. Pregnant or lactating patients also were excluded.

\section{Methods}

Combination ifosfamide and doxorubicin was begun by i.v. infusion after the infusion had been running at $300 \mathrm{~mL} / \mathrm{h}$ for $3 \mathrm{~h}$. Doxorubicin $30 \mathrm{mg} / \mathrm{m}^{2}$ was infused over $5 \mathrm{~min}$ on day 1 , followed by ifosfamide $3750 \mathrm{mg} / \mathrm{m}^{2}$ over $4 \mathrm{~h}$. The continuous i.v. infusion was then slowed to $100 \mathrm{~mL} / \mathrm{h}$ for the remainder of the planned 3 days of fluid supplementation. Mesna $750 \mathrm{mg} / \mathrm{m}^{2}$ was infused i.v. over $15 \mathrm{~min}$ before ifosfamide and repeated 4 and $8 \mathrm{~h}$ later. Day 2 chemotherapy was identical to day 1 treatment. Filgrastim $5 \mu \mathrm{g} / \mathrm{kg}$ was given s.c. daily for 14 days beginning the day following completion of chemotherapy. This chemotherapy regimen (supported by 3 days of i.v. fluids) was repeated every 3 weeks until disease progression occurred or until maximum tolerable doses of doxorubicin were reached $\left(500 \mathrm{mg} / \mathrm{m}^{2}\right)$.

Standard objective response criteria were used for therapeutic assessment, and NCI Common Toxicity Criteria were used to assess drug toxicity. Our plan to better define the objective regression rate of ifosfamide plus doxorubicin in patients with advanced synovial sarcoma involved a two-stage design. If at least five of the first 12 patients experienced tumor regression, a 38-patient second stage of accrual would begin. With 50 patients the study would permit estimation of the true response rate with a $95 \%$ confidence limit of $\pm 14 \%$.

\section{Results}

Our patients received a median of four cycles of chemotherapy (range: 1-6).

Despite the use of filgrastim for 2 weeks after each 2-day ifosfamide + doxorubicin treatment, neutropenia reached grade 3 in all 12 patients (grade 4 in nine of them); and one patient died of treatment related sepsis following the initial cycle of chemotherapy. Except for myelosuppression, no severe drug toxicity has been observed. Five of the 12 patients (42\%) experienced objective partial tumor regression; however, the borderline result data for proceeding and the poor case accrual led us to close the study after completing stage one. With two patients still alive, survival has ranged from 1 to $71+$ months (median 11 months).

\section{Discussion}

By the time our study began in 1994 the previous Phase III E.C.O.G. study ${ }^{3}$ and several others had established ifosfamide plus doxorubicin as a 'standard' regimen for soft tissue sarcomas. Perhaps the sluggish case accrual experienced in the current study was in part a result of the ready access of patients to off-study treatment with this regimen.

As discussed in our 1993 report, the observed objective regression in seven of the eight patients with advanced synovial sarcomas who received this ifosfamide+doxorubicin regimen appeared to be youth related ${ }^{3}$. Because of the small number of patients in the present study, as in the previous one, no better understanding of this suspected youthrelated responsiveness is forthcoming from these results. Median age of the synovial sarcoma patients in the present report was 44 years (range, 26-78), while those receiving this regimen in our 1993 report had a median age of 56 years (range, 37-78), as compared with 61 years (range, 50-74) for the 1993 patients receiving doxorubicin alone.

Remarkably all 13 patients receiving high-dose ifosfamide experienced objective tumor regression in another phase II trial reported by Rosen et al. ${ }^{4}$ All of their patients (median 28 years) were under 40 years of age, the break point shown to segregate chemotherapy responsiveness by age in our broad soft tissue sarcoma report from $1993 .^{3}$ Using vincristine, dactinomycin, dacarbazine, doxorubicin, and cyclophosphamide in various combination regimens from the tradition of children's cancer trials without ifosfamide, Pappo et al. reported that their five metastatic synovial sarcoma patients all 'fared poorly' despite their youth (all under 21 years of age). ${ }^{5}$

In a retrospective analysis of prognostic factors involving 112 patients with primary localized synovial sarcomas from Memorial Sloan-Kettering Cancer Center, Lewis et al. identified a survival trend $(P=0.07)$ favoring patients under 40 years of age. ${ }^{6}$ Another multicenter study of that type including 128 patients from France failed to identify any age-related survival advantage when synovial sarcoma patients above and below age 33 years were compared. $^{7}$

Finally the detailed European Organization for Research and Treatment of Cancer (EORTC) analysis of prognostic factors affecting the outcome of advanced soft tissue sarcoma patients identified youth as favorable for chemotherapy responsiveness $(P=0.001)$ in general. The synovial sarcoma subset, however, were not more responsive, if age-matched, than the overall group. ${ }^{8}$ These results suggest that the apparently greater chemotherapy responsiveness attributed to synovial sarcomas may be simply due to their occurrence generally in younger patients. The EORTC patients with synovial sarcoma also had significantly better survival than most of the other histological types, a fact the authors attributed at least in part to their relative youth.

Recent genetic studies in synovial sarcoma suggest a strong association between the type of translocational gene fusion and histological type (monophasic 
or biphasic), with better prognosis seen in the SYT-SSX2 tumors, which tend to be monophasic. ${ }^{9}$ Perhaps further genetic studies may in the future permit the development of genetically specific molecular therapy to control the aberrant genetic focus found to be driving the growth of an individual synovial sarcoma. Proof of principle for treatment of this type already is available in the case of imatinib mesylate (STI-571) in gastrointestinal stromal sarcomas (GIST). ${ }^{10}$

\section{Acknowledgements}

This study was conducted by the Eastern Cooperative Oncology Group (Robert L. Comis, M.D., Chair) and supported in part by Public Health Service Grants CA23318, CA66636, CA21115, CA13650, CA59307 and from the National Cancer Institute, National Institutes of Health and the Department of Health and Human Services. Its contents are solely the responsibility of the authors and do not necessarily represent the official views of the National Cancer Institute.

\section{References}

1. Chang AE, Rosenberg SA, Glatstein EJ, Antman KH. Sarcomas of soft tissue. In: Devita VT Jr, Hellman S, Rosenberg SA, eds. Cancer Principals and Practice of Oncology, 3rd Edition. Philadelphia, PA: J.B. Lippincott Co. 1989; 1384.

2. Shiraki M, Enterline HT, Brooks JJ, Cooper NS, Hirschl S, Roth JA, Rao UN, Enzinger FM, Amato DA, Borden EC. Pathologic analysis of advanced adult soft tissue sarcomas, bone sarcomas, and mesotheliomas. The Eastern Cooperative Oncology Group experience. Cancer 1989; 64: 484-490.

3. Edmonson J, Ryan L, Blum R, Brooks JSJ, Shiraki M, Frytak S, Parkinson DR. Phase III Eastern Cooperative Oncology Group study of doxorubicin alone versus ifosfamide plus doxorubicin or mitomycin plus doxorubicin plus cisplatin against advanced soft tissue sarcomas. F Clin Oncol 1993; 11: 1269-1275.

4. Rosen G, Forscher C, Lowenbraun S, Eilber F, Eckhardt J, Holmes C, Fu YS. Synovial sarcoma: uniform response of metastases to high dose ifosfamide. Cancer 1994; 73: 2506-2511.

5. Pappo AS, Fontanesi J, Luo X, Rao BN, Parham DM, Hurwitz C, Avery L, Pratt CB. Synovial sarcoma in children and adolescents: the St. Jude Children's Research Hospital experience. F Clin Oncol 1994; 12: 2360-2366.

6. Lewis JJ, Antonescu CR, Leung DHY, Blumberg D, Healey JH, Woodruff JM, Brennan MF. Synovial sarcoma: a multivariate analysis of prognostic factors in 112 patients with primary localized tumors of the extremity. F Clin Oncol 2000; 18: 2087-2094.

7. Trassard M, LeDoussal V, Hacène $K$, Terrier $P$, Ranchère D, Guillou L, Fiche M, Collin F, Vilain MO, Bertrand G, Jacquemier J, Sastre-Garau X, Binh Bui N, Bonichon F, Coindre JM. Prognostic factors in localized primary synovial sarcoma: a multicenter study of 128 adult patients. F Clin Oncol 2001; 19: 525-534.

8. Van Glabbeke M, van Oosterom AT, Oosterhuis JW, Mouridsen H, Crowther D, Somers R, Verweij J, Santoro A, Buesa J, Tursz T. Prognostic factors for the outcome of chemotherapy in advanced soft tissue sarcoma: an analysis of 2,185 patients treated with anthracycline-containing first-line regimens-A European Organization for Research and Treatment of Cancer Soft Tissue and Bone Sarcoma Group Study. F Clin Oncol 1999; 17: 150-157.

9. Landyi M, Antonescu CR, Leung DH, Woodruff JM, Kawai A, Healey JH, Brennan MF, Bridge JA, Neff JR, Barr FG, Goldsmith JD, Brooks JSJ, Goldblum JR, Ali SZ, Shipley J, Cooper CS, Fisher C, Skytting B, Larsson O. Impact of SYT-SSX fusion type on the clinical behavior of synovial sarcoma: a multi-institutional retrospective study of 243 patients. Cancer Res 2002; 62: 135-140.

10. Heinrich MC, Blanke CD, Drucker BJ, Corless CL. Inhibition of KIT tyrosine kinase activity: a novel molecular approach to the treatment of KIT-positive malignancies. f Clin Oncol 2002; 20: 1692-1703. 


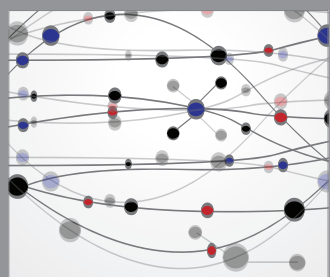

The Scientific World Journal
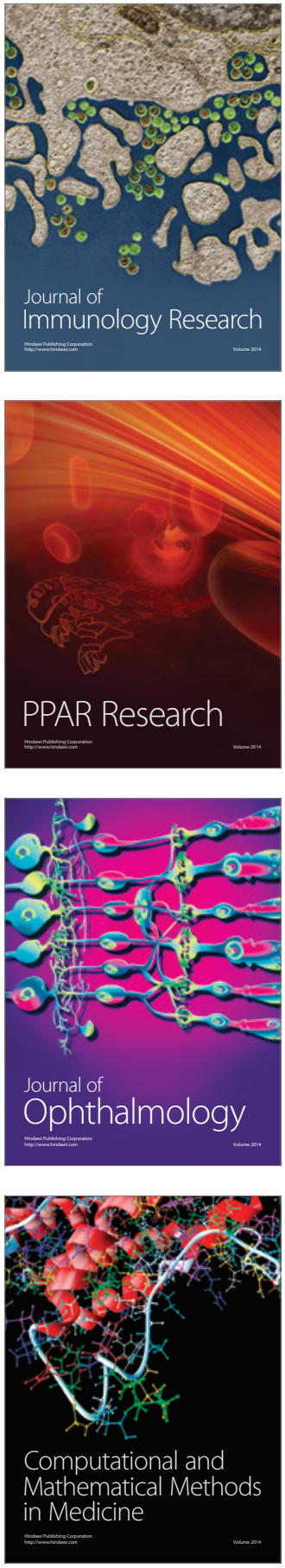

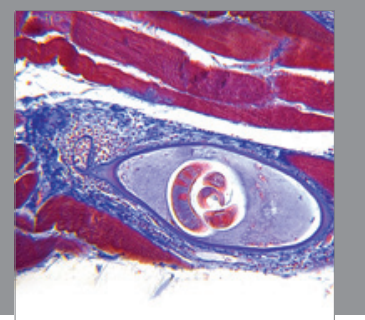

Gastroenterology

Research and Practice
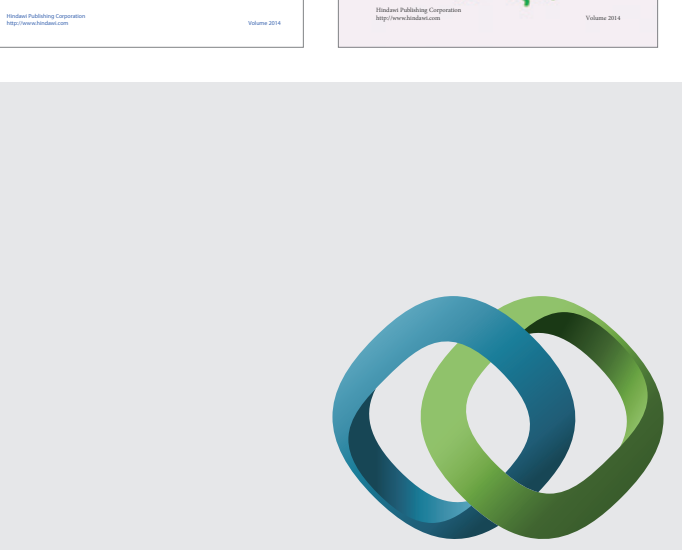

\section{Hindawi}

Submit your manuscripts at

http://www.hindawi.com
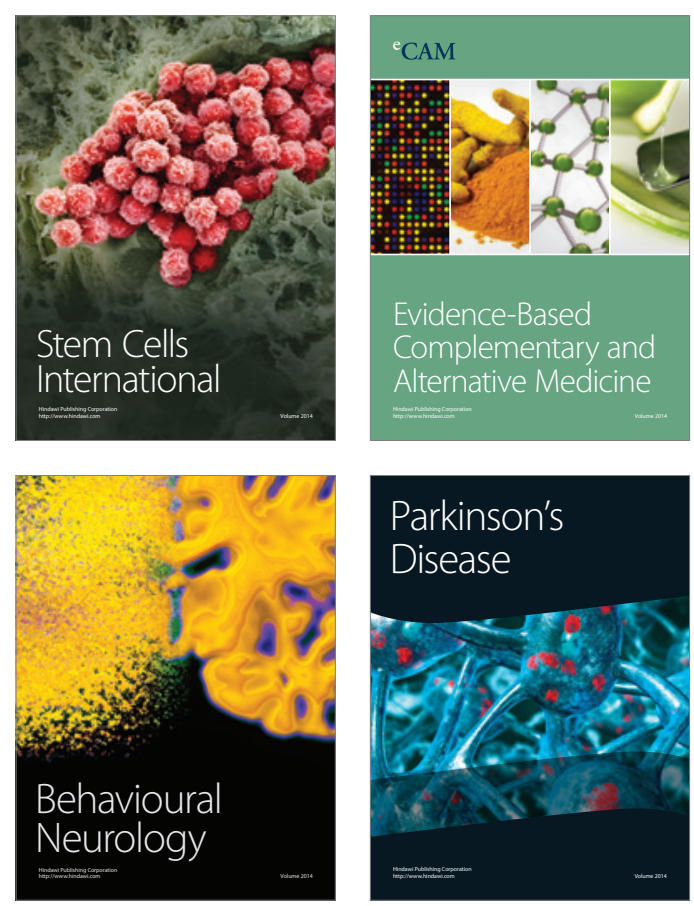

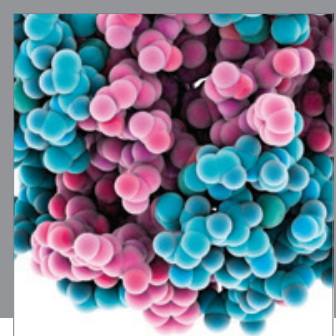

Journal of
Diabetes Research

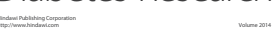

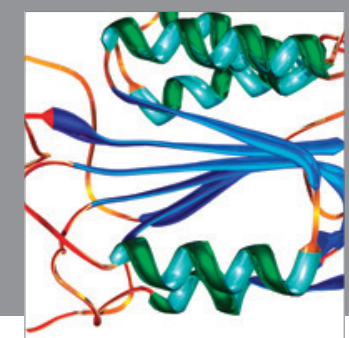

Disease Markers
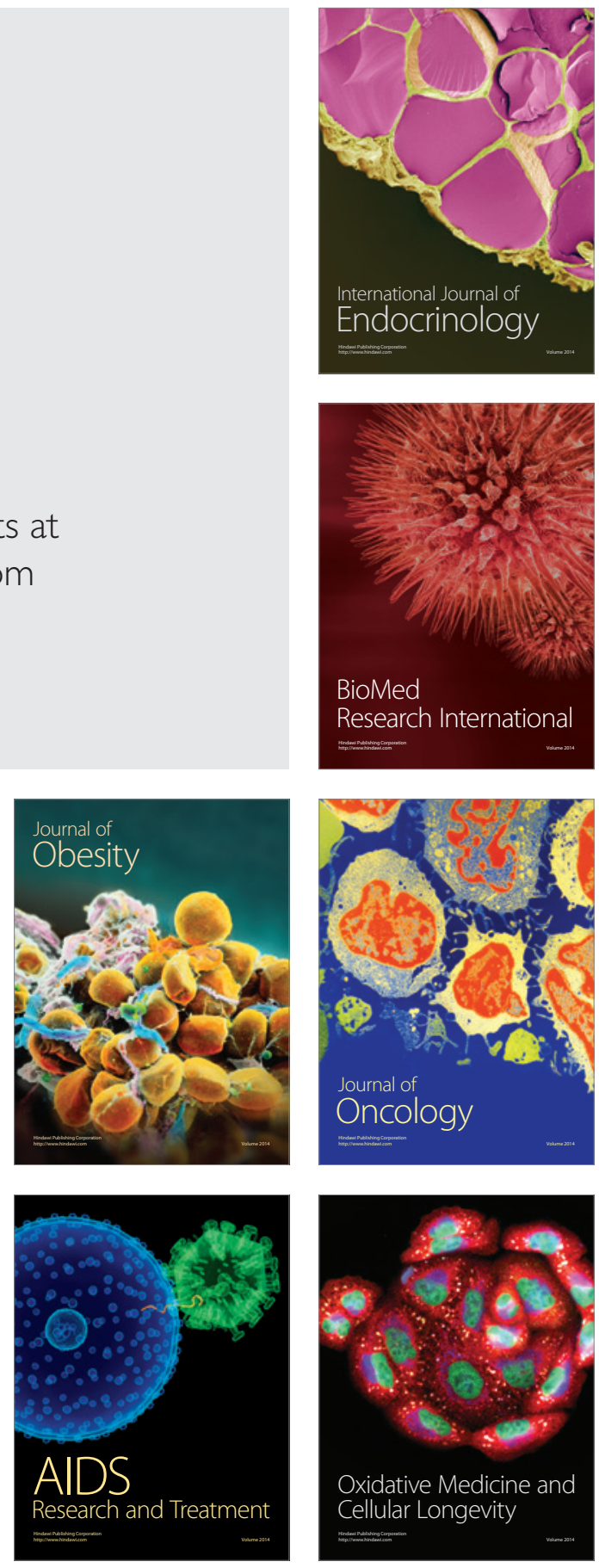